\title{
Ориентационные соотношения при структурном превращении моноклинной и кубической фаз в сульфиде серебра
}

\author{
(C) С.И. Садовников, А.А. Ремпель \\ Институт химии твердого тела Уральского отделения Российской академии наук, \\ 620990 Екатеринбург, Россия \\ E-mail: sadovnikov@ihim.uran.ru
}

Поступила в Редакцию 25 июля 2018 г.

В окончательной редакции 13 февраля 2019 г.

Принята к публикации 25 февраля 2019 г.

\begin{abstract}
На основе экспериментальных данных по высокотемпературной рентгеновской дифракции и просвечивающей электронной микроскопии высокого разрешения сульфида серебра определены ориентационные соотношения между низкотемпературным моноклинным полупроводниковым акантитом $\alpha-\mathrm{Ag}_{2} \mathrm{~S}$ и высокотемпературным объемноцентрированным аргентитом $\beta$ - $\mathrm{Ag}_{2} \mathrm{~S}$. Установлено, что в отличие от акантита в кубическом аргентите возможные расстояния между атомами серебра слишком малы для того, чтобы позиции металлической подрешетки были заняты атомами Ag с вероятностью, равной 1. Показано, что атомные плоскости $(010)$ и (001) акантита параллельны плоскостям (110) и (221) аргентита соответственно. Найденные ориентационные соотношения между акантитом и аргентитом важны для понимания физического действия гетеронаноструктуры $\mathrm{Ag}_{2} \mathrm{~S} / \mathrm{Ag}$, рассматриваемой как потенциальная основа для создания резистивных переключателей и энергонезависимых (nonvolatile) устройств памяти.
\end{abstract}

Ключевые слова: сульфид серебра, фазовый переход, взаимная ориентация акантит, аргентит.

DOI: $10.21883 /$ FTP.2019.07.47874.8964

\section{1. Введение}

Сульфид серебра $\mathrm{Ag}_{2} \mathrm{~S}$ имеет три основные полиморфные модификации: моноклинный акантит $\alpha-\mathrm{Ag}_{2} \mathrm{~S}$, объемноцентрированный кубический (ОЦК) аргентит $\beta-\mathrm{Ag}_{2} \mathrm{~S}$ и высокотемпературный гранецентрированный кубический (ГЦК) сульфид $\gamma-\mathrm{Ag}_{2} \mathrm{~S}$ [1]. Кристаллические структуры моноклинного (пр. гр. $P 2_{1} / c$ ) акантита $\alpha-\mathrm{Ag}_{2} \mathrm{~S}$ и ОЦК (пр.гр. $\operatorname{Im} \overline{3} m$ ) аргентита $\beta-\mathrm{Ag}_{2} \mathrm{~S}$ первоначально были определены на минеральных образцах авторами работ [2,3] и позднее уточнены на синтезированных образцах в работах [4-9]. Согласно [8], нанокристаллический сульфид серебра с размером частиц менее $60 \mathrm{Hм}$ тоже имеет моноклинную (пр. гр. $P 2_{1} / c$ ) структуру типа акантита, но содержит небольшое количество вакансий в подрешетке серебра и имеет нестехиометрический состав $\mathrm{Ag}_{1.93} \mathrm{~S}$.

В равновесных условиях при охлаждении аргентита $\beta-\mathrm{Ag}_{2} \mathrm{~S}$ ниже температуры $450 \mathrm{~K}$ происходит полиморфный фазовый переход с образованием полупроводникового моноклинного акантита $\alpha-\mathrm{Ag}_{2} \mathrm{~S}$ [9]. Это превращение сопровождается искажением ОЦК подрешетки атомов $\mathrm{S}$ до моноклинной подрешетки. Атомы $\mathrm{Ag}$, статически размещенные на позициях 6(b) и 48(j) ОЦК структуры аргентита $[4,7,9]$, концентрируются на позициях моноклинной структуры акантита и заполняют их с вероятностью, близкой к 1.

По данным дифференциального термического и дифференциального термогравиметрического (ДТА-ДТГ) анализа и калориметрических измерений [7,10-12], фазовое превращение акантита $\alpha-\mathrm{Ag}_{2} \mathrm{~S}$ в аргентит происходит при температуре $T_{\text {trans }} \sim 449-452 \mathrm{~K}$, энталь- пия $\Delta H_{\text {trans }}$ фазового превращения $\alpha-\mathrm{Ag}_{2} \mathrm{~S}-\beta-\mathrm{Ag}_{2} \mathrm{~S}$ равна $\sim 4.0 \pm 0.5$ кДж·моль ${ }^{-1}$.

Согласно [2,13], структуру акантита $\alpha-\mathrm{Ag}_{2} \mathrm{~S}$ можно рассматривать как результат искажения ОЦК подрешетки атомов серы $\mathrm{S}$ в структуре аргентита $\beta-\mathrm{Ag}_{2} \mathrm{~S}$. Действительно, элементарная ячейка моноклинного (пр.гр. $P 2_{1} / c$ ) акантита $\alpha-\mathrm{Ag}_{2} \mathrm{~S}$, предложенная в работе [2], имеет оси, которые можно представить как комбинации осей $\mathbf{a}_{b c c}, \mathbf{b}_{b c c}$ и $\mathbf{c}_{b c c}$ элементарной ячейки ОЦК аргентита: $\mathbf{a}_{P 2_{1} / c} \approx\left(\mathbf{a}_{b c c}+\mathbf{b}_{b c c}-\mathbf{c}_{b c c}\right) / 2$, $\mathbf{b}_{P 2_{1} / c} \approx\left(\mathbf{a}_{b c c}-\mathbf{b}_{b c c}\right)$ и $\mathbf{c}_{P 2_{1} / c} \approx 2 \mathbf{c}_{b c c}$.

В работе [9] показано, что обратимое превращение „акантит-аргентит“ играет важную роль в действии гетеронаноструктуры $\mathrm{Ag}_{2} \mathrm{~S} / \mathrm{Ag}$ как потенциального резистивного переключателя. Однако ориентационные соотношения между этими двумя фазами сульфида серебра не были выяснены.

В связи с этим в настоящей работе методом просвечивающей электронной микроскопии высокого разрешения проведено in situ наблюдение фазового перехода „акантит $\alpha-\mathrm{Ag}_{2} \mathrm{~S}$-аргентит $\beta-\mathrm{Ag}_{2} \mathrm{~S}$ “ в сульфиде серебра и определены ориентационные соотношения между акантитом и аргентитом.

\section{2. Образцы и экспериментальные методы}

Для определения структуры акантита и аргентита и ориентационных соотношений между этими фазами использовали крупно- и нанокристаллический порошки сульфида серебра со средним размером частиц $\sim 850$ 
Таблица 1. Кристаллические структуры моноклинного нанопорошка $\alpha-\mathrm{Ag}_{1.93} \mathrm{~S}$ со структурой акантита и размером частиц $\sim 45$ нм при $300 \mathrm{~K}[8]$ и кубического сульфида серебра $\beta-\mathrm{Ag}_{2} \mathrm{~S}$ со структурой аргентита при $503 \mathrm{~K}[7,9,13]$

\begin{tabular}{|c|c|c|c|c|c|c|c|}
\hline \multirow{2}{*}{$\begin{array}{c}\text { Фаза } \\
\text { и ее пр. гр. }\end{array}$} & \multirow{2}{*}{$\begin{array}{c}\text { Параметры } \\
\text { ячейки (нм) }\end{array}$} & \multirow{2}{*}{ Атом } & \multirow{2}{*}{$\begin{array}{c}\text { Позиция } \\
\text { и кратность }\end{array}$} & \multicolumn{3}{|c|}{ Атомные координаты } & \multirow{2}{*}{$\begin{array}{c}\text { Степень } \\
\text { заполнения }\end{array}$} \\
\hline & & & & $x / a$ & $y / b$ & $z / c$ & \\
\hline $\begin{array}{c}\alpha-\mathrm{Ag}_{1.93} \mathrm{~S} \\
\left(P 2_{1} / c\right) \\
{ }^{*} Z=4\end{array}$ & $\begin{array}{c}a=0.4234(3) \\
b=0.6949(3) \\
c=0.9549(5) \\
\beta=125.43^{\circ}\end{array}$ & $\begin{array}{l}\mathrm{Ag} 1 \\
\mathrm{Ag} 2 \\
\mathrm{~S}\end{array}$ & $\begin{array}{l}4(\mathrm{e}) \\
4(e) \\
4(e)\end{array}$ & $\begin{array}{l}0.0715 \\
0.2736 \\
0.4920\end{array}$ & $\begin{array}{l}0.0151(0) \\
0.8240(9) \\
0.2339(8)\end{array}$ & $\begin{array}{l}0.3093(9) \\
0.0625(0) \\
0.1321(1)\end{array}$ & $\begin{array}{l}0.97 \\
0.96 \\
1.00\end{array}$ \\
\hline $\begin{array}{c}\beta-\mathrm{Ag}_{2} \mathrm{~S} \\
(\operatorname{Im} \overline{3} m) \\
Z=2\end{array}$ & $a=0.4874(1)$ & $\begin{array}{l}\mathrm{Ag} 1 \\
\mathrm{Ag} 2 \\
\mathrm{~S}\end{array}$ & $\begin{array}{c}6(b) \\
48(j) \\
2(a)\end{array}$ & $\begin{array}{l}0 \\
0 \\
0\end{array}$ & $\begin{array}{c}0.5 \\
0.3306(5) \\
0\end{array}$ & $\begin{array}{c}0.5 \\
0.4122(7) \\
0\end{array}$ & $\begin{array}{c}0.0978 \\
0.0711 \\
1.00\end{array}$ \\
\hline
\end{tabular}

Примечание. ${ }^{*} Z$ — число формульных единиц в элементарной ячейке.

и $\sim 50$ нм соответственно. Методики синтеза порошков сульфида серебра описаны ранее $[13,14]$.

Кристаллическую структуру синтезированных порошков сульфида серебра исследовали на дифрактометре Shimadzu XRD-7000 в $\mathrm{Cu} K_{\alpha_{1}}$-излучении в интервале углов $2 \theta=20-95^{\circ}$ с шагом $\Delta(2 \theta)=0.02^{\circ}$ и временем экспозиции 10 с в каждой точке. Методика высокотемпературного in situ рентгеновского исследования, выполненного на дифрактометре X'Pert PRO MPD (Panalytical) с печью Anton Paar HTK-1200 Oven, описана в [9,13].

Определение параметров кристаллической решетки и окончательное уточнение структуры синтезированных порошков сульфида серебра проводили с помощью программного пакета X'Pert HighScore Plus [15].

Наблюдение за изменением кристаллической структуры при фазовом переходе $\alpha-\mathrm{Ag}_{2} \mathrm{~S}$ (акантит) $-\beta-\mathrm{Ag}_{2} \mathrm{~S}$ (аргентит) проводили на наночастицах сульфида серебра методом просвечивающей электронной микроскопии высокого разрешения HRTEM на микроскопе JEOL JEM-2100 с решеточным разрешением 0.14 нм. Для исследования коллоидные растворы наночастиц $\mathrm{Ag}_{2} \mathrm{~S}$ наносили на медную сетку. Нагрев наночастиц $\mathrm{Ag}_{2} \mathrm{~S}$ осуществляли непосредственно в электронном микроскопе, регулируя энергию электронного пучка. Ранее [13] методом сканирующей электронной микроскопии удалось визуализировать динамику фазового превращения „акантит-аргентит“ в нанокристаллическом сульфиде серебра, т.е. образование, рост и форму зародышей аргентита на поверхности частиц акантита, однако взаимная кристаллографическая ориентация этих фаз сульфида серебра не была установлена.

\section{3. Ориентационные соотношения между акантитом и аргентитом}

Количественный анализ рентгенограмм крупнокристаллического порошка сульфида серебра при 300 и $503 \mathrm{~K}$ [13] и рентгенограмм нанопорошка сульфида серебра при 300 и $463 \mathrm{~K}$, полученных нами ранее в работах $[8,13]$, и сравнение их с данными $[6,8]$ показали, что рентгенограммы крупно- и нанокристаллического порошков, снятые при $300 \mathrm{~K}$, содержат набор дифракционных отражений моноклинного (пр.гр. $P 22_{1} / c$ ) акантита $\alpha-\mathrm{Ag}_{2} \mathrm{~S}$. Моноклинные крупно- и нанокристаллический сульфиды серебра имеют состав $\mathrm{Ag}_{2} \mathrm{~S}$ и $\mathrm{Ag}_{1.93} \mathrm{~S}$ соответственно. В моноклинной (пр.гр. $P 2_{1} / c$ ) фазе сульфида серебра атомы серы $\mathrm{S}$ полностью занимают позиции 4(e).

Уточнение рентгенограммы крупнокристаллического сульфида серебра, полученной при температуре $503 \mathrm{~K}$, показало, что при этой температуре крупнокристаллический сульфид серебра содержит одну фазу с кубической (пр.гр. $\operatorname{Im} \overline{3} m)$ структурой типа аргентита $\beta-\mathrm{Ag}_{2} \mathrm{~S}$ [13]. Согласно высокотемпературным рентгеновским данным, элементарная ячейка аргентита $\beta-\mathrm{Ag}_{2} \mathrm{~S}$ включает две формульные единицы $\mathrm{Ag}_{2} \mathrm{~S}$. Два атома серы $\mathrm{S}$ занимают кристаллографические позиции $2(a)$ и образуют ОЦК подрешетку. Четыре атома серебра Ag статистически распределены по 54 позициям $6(b)$ и $48(j)$ с вероятностями заполнения $\sim 0.0978$ и $\sim 0.0711$ соответственно. Сопоставление кристаллических структур моноклинного акантита и кубического аргентита представлено в табл. 1.

В целом рентгеновское in situ исследование сульфида серебра обнаружило только акантит при $T \leq 433 \mathrm{~K}$ и только аргентит при $T>453 \mathrm{~K}$. Никакие другие фазы не обнаружены. С учетом этого и данных [7,9-13] при нагреве моноклинного акантита $\alpha-\mathrm{Ag}_{2} \mathrm{~S}$ до температуры $\sim 449-450 \mathrm{~K}$ происходит полиморфный фазовый переход с образованием ОЦК аргентита $\beta-\mathrm{Ag}_{2} \mathrm{~S}$.

Схема смещений атомов $\mathrm{S}$ из ОЦК подрешетки аргентита и моноклинно искаженная подрешетка атомов $\mathrm{S}$, построенная с учетом координат атомов серы в моноклиной (пр.гр. $\left.P 2_{1} / c\right)$ фазе $\alpha-\mathrm{Ag}_{2} \mathrm{~S}$ (см. табл. 1), показана на рис. 1 . В результате смещений атомов $\mathrm{S}$ из ОЦК позиций 2(a) решетки аргентита возникают моноклинные трансляции $\mathbf{a}, \mathbf{b}$ и $\mathbf{c}$, направление которых можно представить как комбинации базисных трансляций ОЦК решетки аргентита: $\mathbf{a}\left\|[11 \overline{1}]_{b c c} / 2, \mathbf{b}\right\|[1 \overline{1} 0]_{b c c}$ и с $\|[001]_{b c c}$. Однако по абсолютной величине моноклинные трансляции $|\mathbf{a}|,|\mathbf{b}|$ и $|\mathbf{c}|$ несколько больше, чем $\sqrt{ } 3\left(a_{b c c} / 2\right), \sqrt{ } 2 a_{b c c}$ и $2 a_{b c c}$. Для объяснения этого рассмотрим межатомные расстояния в аргентите. 


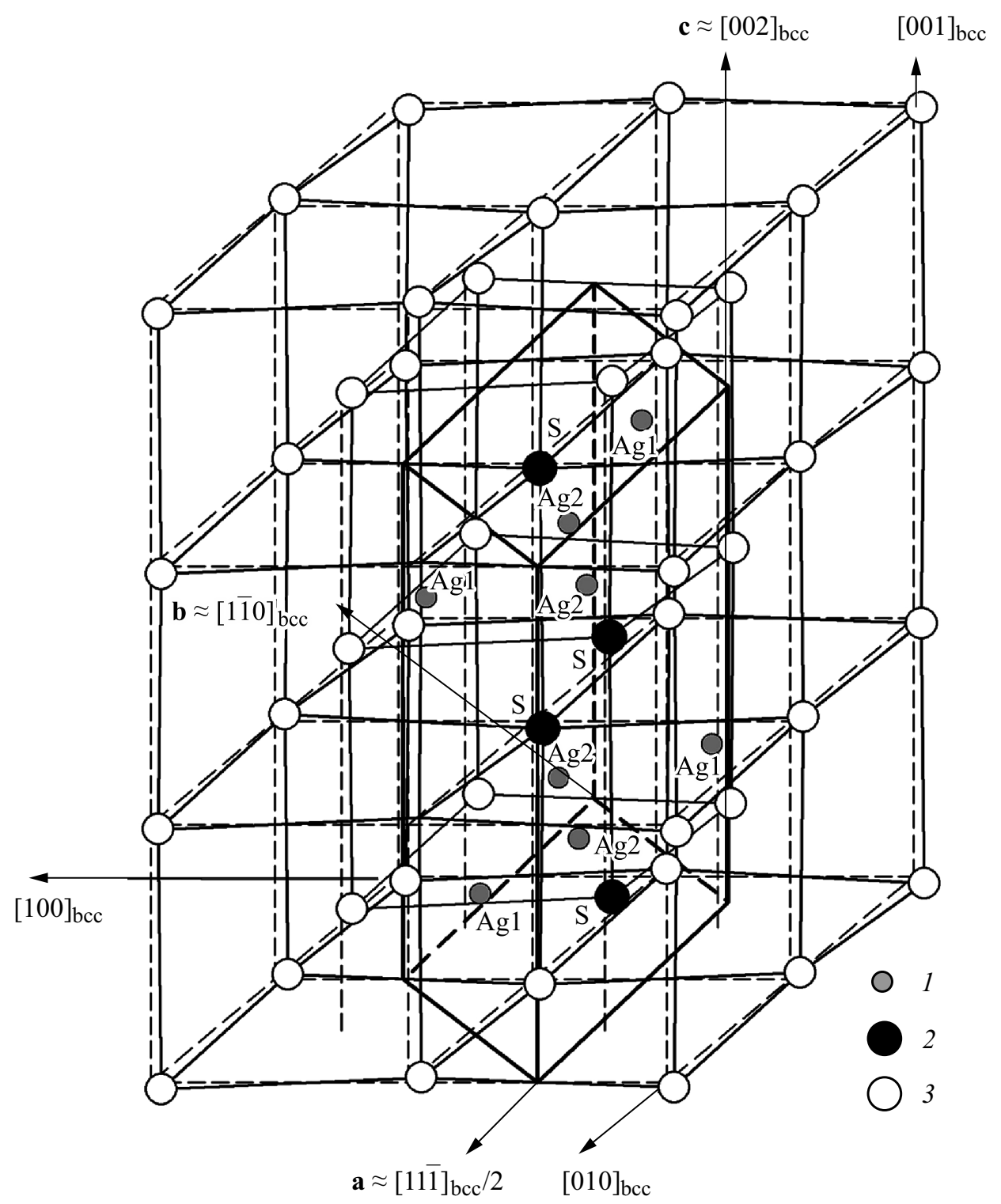

Рис. 1. Схема смещений атомов $\mathrm{S}$ из положений ОЦК подрешетки аргентита и размещение атомов $\mathrm{S}$ в моноклинном акантите. Контуры решетки кубического аргентита показаны пунктиром, искаженная из-за смещений атомов $\mathrm{S}$ решетка аргентита показана сплошной линией. Моноклинная (пр. гр. $\left.P 2_{1} / c\right)$ элементарная ячейка акантита $\alpha-\mathrm{Ag}_{2} \mathrm{~S}$ показана толстой сплошной линией. $(1)$ и (2) - атомы $\mathrm{Ag}$ и $\mathrm{S}$, расположенные в моноклинной элементарной ячейке акантита $\alpha-\mathrm{Ag}_{2} \mathrm{~S},(3)-$ атомы $\mathrm{S}$, расположенные вне моноклинной элементарной ячейки.

В табл. 2 с учетом найденных периода решетки и координат атомов серебра и серы в аргентите (см. табл. 1) приведены рассчитанные межатомные (межузельные) расстояния для разных координационных сфер (КС) кристаллической структуры кубического (пр. гр. $\operatorname{Im} \overline{3} m$ ) аргентита $\beta-\mathrm{Ag}_{2} \mathrm{~S}$. Поскольку степень заполнения узлов металлической подрешетки атомами серебра очень мала, более правильно говорить о расстояниях между узлами, на которых могут находиться атомы Ag.

Использование найденных данных по температурным зависимостям параметров кристаллических решеток моноклинного акантита и кубического аргентита [14] позволяет оценить величину межатомных расстояний в этих фазах при сопоставимых температурах, близких к температуре $T_{\text {trans }}$ превращения „акантит-аргентит“. В кристаллической решетке моноклинного акантита $\alpha-\mathrm{Ag}_{2} \mathrm{~S}$ при температуре $433 \mathrm{~K}$ наименьшие расстояния между атомами $\mathrm{S}$ и Ag1 лежат в интервале от 0.2516 до 0.3066 нм, атомами $\mathrm{S}$ и $\mathrm{Ag} 2$ - от 0.2562 до 0.2950 нм. Расстояние между атомами Ag1 и $\mathrm{Ag} 1$ в акантите $\alpha-\mathrm{Ag}_{2} \mathrm{~S}$ при $433 \mathrm{~K}$ равно $0.3353 \mathrm{Hм}$, наименьшие расстояния между атомами Ag1 и Ag2 лежат в интервале от 0.3087 до 0.3205 нм. Радиус иона $\mathrm{Ag}^{+}$равен $\sim 0.126 \mathrm{Hм}$ [16]. С учетом этого ясно, что атомы (ионы) серебра в моноклинном акантите находятся на достаточно больших расстояниях друг от друга и поэтому занимают свои кристаллографические позиции с вероятностью, равной 1 . 
$a$
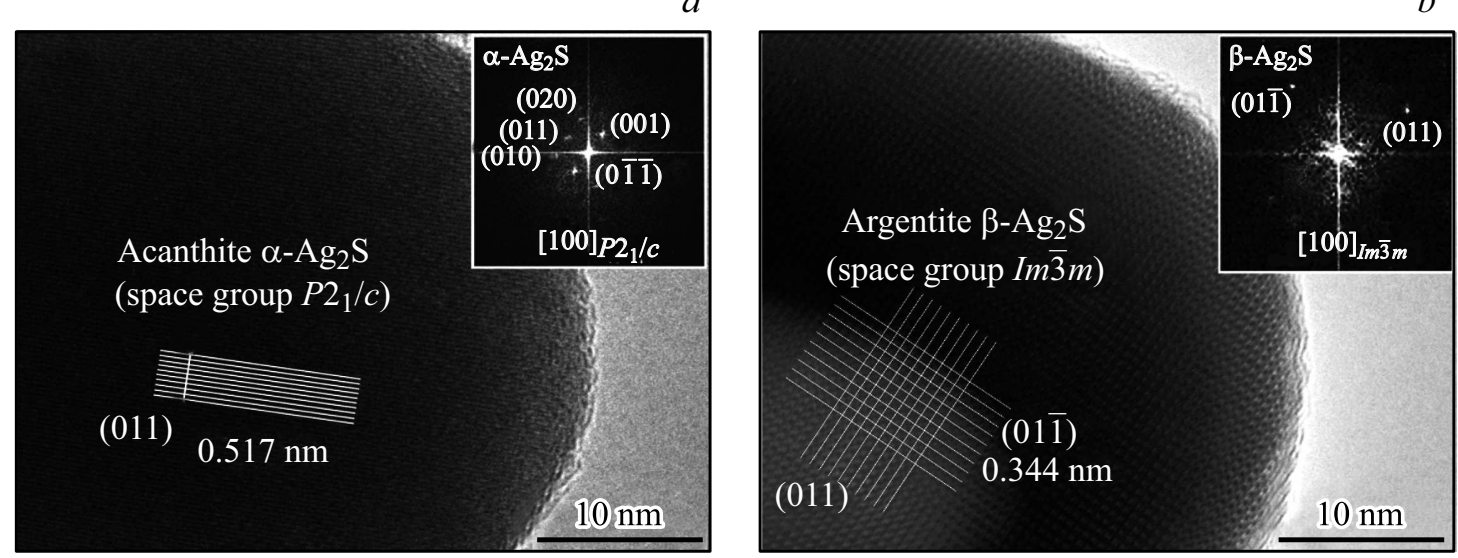

Рис. 2. HRTЕМ-изображения наночастиц сульфида серебра: $a$ - межплоскостное расстояние 0.517 нм, наблюдаемое до нагрева, соответствует моноклинному сульфиду серебра со структурой акантита $\alpha-\mathrm{Ag}_{2} \mathrm{~S} ; b$ - межплоскостное расстояние 0.344 нм, наблюдаемое после нагрева, соответствует кубическому сульфиду серебра со структурой аргентита $\beta$-Ag 2 S. На вставках показаны картины электронной дифракции, полученные фурье-преобразованием (FFT) HRTEM-изображений.

В кубическом аргентите $\beta-\mathrm{Ag}_{2} \mathrm{~S}$ возможные расстояния между атомами серы и серебра и между атомами серебра при близкой температуре $453 \mathrm{~K}$ значительно меньше (см. табл. 2). Период решетки аргентита при $453 \mathrm{~K}$ равен 0.4861 нм. В кристаллической решетке кубического аргентита $\beta-\mathrm{Ag}_{2} \mathrm{~S}$ при температуре $453 \mathrm{~K}$ возможные наименьшие расстояния между атомами $\mathrm{Ag} 1$ и $\mathrm{Ag} 1$ равны 0.2431 нм, между атомами $\mathrm{Ag} 1$ и $\mathrm{Ag} 2$ лежат в интервале от 0.0927 до 0.3256 нм, между атомами $\mathrm{Ag} 2$ и $\mathrm{Ag} 2$ составляют от 0.0561 до 0.3002 нм. Узлы подре-

Таблица 2. Межатомные (межузельные) расстояния $d$ в кубическом (пр. гр. $\operatorname{Im} \overline{3} m)$ аргентите $\beta$ - $\mathrm{Ag}_{2} \mathrm{~S}$ при температуре $453 \mathrm{~K}$

\begin{tabular}{|c|c|c|c|c|c|}
\hline $\begin{array}{c}\text { Пара атомов } \\
\text { (узлов) }\end{array}$ & ${ }^{*} \mathrm{KC}$ & $\begin{array}{c}\text { Расстояние } \\
d, \text { нм }\end{array}$ & $\begin{array}{c}\text { Пара атомов } \\
\text { (узлов) }\end{array}$ & ${ }^{*} \mathrm{KC}$ & $\begin{array}{c}\text { Расстояние } \\
d, \text { нм }\end{array}$ \\
\hline $\begin{array}{l}\mathrm{Ag} 1-\mathrm{S} \\
6(b)-2(a)\end{array}$ & 1 & 0.24307 & $\begin{array}{c}\mathrm{Ag} 2-\mathrm{Ag} 2 \\
48(j)-48(j)\end{array}$ & $\begin{array}{l}5 \\
6\end{array}$ & $\begin{array}{l}0.15013 \\
0.16466\end{array}$ \\
\hline $\begin{array}{c}\mathrm{Ag} 2-\mathrm{S} \\
48(j)-2(a)\end{array}$ & $\begin{array}{l}1 \\
2\end{array}$ & $\begin{array}{l}0.25691 \\
0.26015\end{array}$ & & $\begin{array}{l}7 \\
8\end{array}$ & $\begin{array}{l}0.17674 \\
0.18543\end{array}$ \\
\hline $\begin{array}{l}\mathrm{Ag} 1-\mathrm{Ag} 1 \\
6(b)-6(b)\end{array}$ & 1 & 0.24307 & & $\begin{array}{r}9 \\
10\end{array}$ & $\begin{array}{l}0.19607 \\
0.22352\end{array}$ \\
\hline $\begin{array}{l}\mathrm{Ag} 1-\mathrm{Ag} 2 \\
6(b)-48(j)\end{array}$ & $\begin{array}{l}1 \\
2 \\
3 \\
4 \\
5 \\
6\end{array}$ & $\begin{array}{l}0.09271 \\
0.16630 \\
0.21670 \\
0.29451 \\
0.29734 \\
0.32561\end{array}$ & & $\begin{array}{l}11 \\
12 \\
13 \\
14 \\
15 \\
16\end{array}$ & $\begin{array}{l}0.22732 \\
0.24279 \\
0.25044 \\
0.25996 \\
0.26951 \\
0.28343\end{array}$ \\
\hline $\begin{array}{c}\mathrm{Ag} 2-\mathrm{Ag} 2 \\
48(j)-48(j)\end{array}$ & $\begin{array}{l}1 \\
2 \\
3 \\
4\end{array}$ & $\begin{array}{l}0.05611 \\
0.08530 \\
0.09893 \\
0.13112\end{array}$ & & $\begin{array}{l}17 \\
18 \\
19 \\
20\end{array}$ & $\begin{array}{l}0.28570 \\
0.29491 \\
0.29756 \\
0.30020\end{array}$ \\
\hline
\end{tabular}

Примечание. ${ }^{*} \mathrm{KC}$ - координационная сфера. шетки серебра, особенно $48(j)$, расположены настолько близко друг к другу, что размещение иона $\mathrm{Ag}^{+}$в одном из них делает невозможным заполнение ближайшего соседнего узла другим ионом серебра, так как диаметр иона $\mathrm{Ag}^{+}$больше, чем расстояние между этими узлами. Действительно, межатомные расстояния в кубическом аргентите таковы, что при наличии иона серебра в узле 6(b) другой ион $\mathrm{Ag}^{+}$может занимать один из узлов $48(j)$, находящийся лишь в 4 или 5 координационной сфере на расстоянии 0.2945 или 0.2973 нм от узла $6(b)$. Аналогично, если ион $\mathrm{Ag}^{+}$занимает один из узлов $48(j)$, то другой ион $\mathrm{Ag}^{+}$может находиться в узле $48(j)$, расположенном на расстоянии не менее 0.252 нм от первого узла, т.е. не ближе чем в 14 координационной сфере.

Таким образом, в кубическом аргентите возможные расстояния между атомами серебра слишком малы для того, чтобы позиции 6(b) и 48(j) были заняты атомами $\mathrm{Ag}$ с вероятностью, равной 1. По этой причине степени заполнения позиций $6(b)$ и $48(j)$ атомами $\mathrm{Ag}$ (иначе говоря, вероятности обнаружения атомов $\mathrm{Ag}$ на позициях $6(b)$ и $48(j))$ очень малы и составляют менее 0.1 (см. табл. 1). Физически это означает, что в решетке кубического аргентита 4 атома серебра находятся в непрерывном движении по 54 возможным для них кристаллографическим позициям. Именно это непрерывное движение атомов $\mathrm{Ag}$ обеспечивает стабильность кристаллической решетки кубического аргентита и его суперионную проводимость.

В акантите вследствие моноклинного искажения решетки атомы (ионы) серебра находятся на достаточно больших (больше, чем в аргентите) расстояниях друг от друга и поэтому занимают свои кристаллографические позиции 4(e) с вероятностью, близкой к 1.

Синтезированный моноклинный нанопорошок $\alpha-\mathrm{Ag}_{2} \mathrm{~S}$ в микроскопе JEOL JEM-2010 нагревали электронным пучком. Нагрев наночастиц сульфида серебра до разных температур проводили, регулируя энергию электронно- 
го пучка. При нагреве наночастицы $\mathrm{Ag}_{2} \mathrm{~S}$ от комнатной температуры до $\sim 450 \mathrm{~K}$ сохраняется моноклинная структура с увеличением периодов решетки. Нагрев до 455-460 K сопровождается перестройкой моноклинной структуры акантита $\alpha-\mathrm{Ag}_{2} \mathrm{~S}$ в кубическую структуру аргентита $\beta-\mathrm{Ag}_{2} \mathrm{~S}$. Дальнейший нагрев приводит к увеличению периода решетки кубического аргентита. При уменьшении энергии электронного пучка период решетки аргентита уменьшается, При температуре ниже $\sim 455 \mathrm{~K}$ происходит переход от кубической структуры аргентита к моноклинной структуре акантита.

Изображения наночастиц сульфида серебра до и после радиационного нагрева, полученные с помощью просвечивающей электронной микроскопии высокого разрешения HRTEM (рис. 2), подтверждают образование аргентита.

HRTЕМ-изображение наночастицы сульфида серебра до радиационного нагрева представлено на рис. 2, $a$. На верхней вставке показана картина электронной дифракции, полученная фурье-преобразованием (Fast Fourier Transform (FFT)) этого изображения. На рис. 2, $a$ хорошо видно межплоскостное расстояние 0.517 нм, которое совпадает с расстоянием между атомными плоскостями (011) сульфида серебра с моноклинной (пр. гр. $P 2_{1} / c$ ) структурой акантита $\alpha-\mathrm{Ag}_{2} \mathrm{~S}$.

Картина электронной дифракции подтверждает моноклинную структуру наночастицы $\mathrm{Ag}_{2} \mathrm{~S}$ при комнатной температуре. Выделенная область электронной дифракции содержит пятна (001), (010), (011) и (020) (рис. 2,a), соответствующие моноклинному (пр.гр. $P 2_{1} / c$ ) полупроводниковому акантиту $\alpha-\mathrm{Ag}_{2} \mathrm{~S}$. Эти отражения наблюдаются вдоль оси зоны [100] моноклинного акантита $\alpha-\mathrm{Ag}_{2} \mathrm{~S}$.

HRTЕМ-изображение наночастицы сульфида серебра, нагретой электронным пучком до температуры выше, чем температура перехода $T_{\text {trans, }}$, показано на рис. $2, b$. На вставке представлена картина электронной дифракции, полученная Фурье-преобразованием этого HRTEMизображения. Дифракционные пятна на картине электронной дифракции (рис. 2,b) имеют кристаллографические индексы (011) и (01) куббического (пр. гр. $\operatorname{Im} \overline{3} m)$ аргентита и наблюдаются вдоль оси зоны [100] кубического аргентита $\beta-\mathrm{Ag}_{2} \mathrm{~S}$.

Как было отмечено, моноклинная (пр.гр. $P 2_{1} / c$ ) структура акантита $\alpha-\mathrm{Ag}_{2} \mathrm{~S}$ является результатом небольших смещений атомов серы из положений объемноцентрированной (пр. гр. $\operatorname{Im} \overline{3} m$ ) решетки аргентита $\beta-\mathrm{Ag}_{2} \mathrm{~S}$. При превращении акантита в аргентит атомные акантита плоскости $(010)_{P 2_{1} / c} \|(020)_{P 2_{1} / c}$ и $(001)_{P 2_{1} / c}$ преобразуются в плоскости $(1 \overline{1} 0)_{\operatorname{Im} \overline{3} m}$ и $(221)_{\operatorname{Im} \overline{3} m}$ aргентита. Между этими плоскостями акантита и аргентита выполняются следующие ориентационные соотношения: $(010)_{P 2_{1} / c}\left\|(1 \overline{1} 0)_{\operatorname{Im} \overline{3} m},(020)_{P 2_{1} / c}\right\|(1 \overline{1} 0)_{\operatorname{Im} \overline{3} m}$ и $(001)_{P 2_{1} / c} \|(221)_{\operatorname{Im} \overline{3} m}$, соответствующие ориентации осей $[100]_{P 2_{1} / c} \|[110]_{\operatorname{Im} \overline{3} m}$.

Атомная плоскость $(0 \overline{1} 1)_{P 2_{1} / c}^{d}$ акантита без учета смещений атомов из позиций решетки аргентита параллельна плоскости $(\overline{3} 13 / 2)_{\operatorname{Im} \overline{3} m}$. Реальная (с учетом смещений атомов) атомная плоскость $(0 \overline{1} 1)_{P 2_{1} / c}$ акантита проходит через атомы Ag1 с координатами $\left(\begin{array}{lll}0.0715 & 0.0151 & 0.3094\end{array}\right)$ и (0.0715 0.48490 .8094$)$ (табл. 1) и аналогичные атомы в соседних элементарных ячейках, расстояние между плоскостями $(0 \overline{1} 1)_{P 2_{1} / c}$ акантита равно $\sim 0.517$ нм. Плоскости $(0 \overline{1} 1)_{P 2_{1} / c}$ и $(\overline{3} 13 / 2)_{\operatorname{Im} \overline{3} m}$ В результате смещений атомов оказываются не параллельными, а направленными друг относительно друга под небольшим углом $\sim 1.86^{\circ}$. Атомная плоскость $(011)_{P 2_{1} / c}$ акантита, проходящая через атомы $\mathrm{Ag} 2$ с координатами

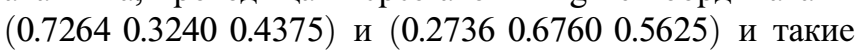
же атомы в соседних элементарных ячейках, параллельна плоскости $(1 \overline{3} 3 / 2)_{\operatorname{Im} \overline{3} m}$ аргентита.

Атомная плоскость (001) $2_{2} /{ }_{1}$ акантита проходит через атомы Ag2 с координатой $z=0.0625$ (см. табл. 1) в соседних элементарных ячейках и потому параллельна плоскости (221) Im $\overline{3} m$ аргентита. Расстояние между плоскостями $(001)_{P 2_{1} / c}$ составляет $\sim 0.775 \mathrm{HM}$.

Определение ориентационных соотношений между моноклинным акантитом $\alpha-\mathrm{Ag}_{2} \mathrm{~S}$ и кубическим аргентитом $\beta-\mathrm{Ag}_{2} \mathrm{~S}$ важно для понимания физического действия гетеронаноструктуры $\mathrm{Ag}_{2} \mathrm{~S} / \mathrm{Ag}$, связанного с превращением „акантит-аргентит“. Гетеро-наноструктура $\mathrm{Ag}_{2} \mathrm{~S} / \mathrm{Ag}$ рассматривается как потенциальная основа для создания резистивных переключателей и энергонезависимых (nonvolatile) устройств памяти [9,17-19].

\section{4. Заключение}

Высокотемпературное in situ рентгено-дифракционное и электронно-микроскопическое изучение сульфида серебра подтвердило наличие обратимого фазового перехода между моноклинным акантитом $\alpha-\mathrm{Ag}_{2} \mathrm{~S}$ и кубическим аргентитом $\beta-\mathrm{Ag}_{2} \mathrm{~S}$, происходящего при температуре $\sim 443-453 \mathrm{~K}$. Образование акантита сопровождается моноклинным искажением неметаллической ОЦК подрешетки аргентита, благодаря чему расстояния между атомами (ионами) серебра увеличиваются по сравнению с аналогичными расстояниями в аргентите, а вероятности заполнения кристаллографических позиций атомами Ag достигают 1.

Несмотря на наличие смешений, некоторые атомные плоскости акантита остаются параллельными плоскостям аргентита: $\quad(010)_{P 2_{1} / c} \|(1 \overline{1} 0)_{\operatorname{Im} \overline{3} m}$, $(020)_{P 2_{1} / c} \|(1 \overline{1} 0)_{\operatorname{Im} \overline{3} m}$ и $(001)_{P 2_{1} / c} \|(221)_{\operatorname{Im} \overline{3} m}$. Другие плоскости, в частности плоскость $(0 \overline{1} 1)_{P 2_{1} / c}$ акантита в результате смещений атомов направлены под углом $\sim 1.86^{\circ}$ к плоскости $(\overline{3} 13 / 2)_{\operatorname{Im} \overline{3} m}$ аргентита.

\section{Благодарности}

Авторы благодарят Е.Ю. Герасимова и А.В. Чукина за помощь в электронно-микроскопических и высокотемпературных рентгеновских измерениях.

\section{Конфликт интересов}

Авторы заявляют, что у них нет конфликта интересов. 


\section{Список литературы}

[1] R.C. Sharma, Y.A. Chang. Bull. Alloy Phase Diagrams, 7, 263 (1986).

[2] R. Sadanaga, S. Sueno. Mineralog. J. Jpn., 5, 124 (1967).

[3] L.S. Ramsdell. Amer. Mineralogist., 28, 401 (1943).

[4] T. Blanton, S. Misture, N. Dontula, S. Zdzieszynski. Powd. Diffraction, 26, 110 (2011).

[5] R.J. Cava, F. Reidinger, B.J. Wuensch. J. Solid State Chem., 31, 69 (1980).

[6] S.I. Sadovnikov, A.I. Gusev, A.A. Rempel. Superlat. Microstr., 83, 35 (2015).

[7] S.I. Sadovnikov, A.I. Gusev, A.A. Rempel. Phys. Chem. Chem. Phys., 17, 20495 (2015).

[8] S.I. Sadovnikov, A.I. Gusev, A.A. Rempel. Phys. Chem. Chem. Phys., 17, 12466 (2015).

[9] А.И. Гусев, С.И. Садовников. ФТП, 50, 694 (2016).

[10] C.M. Perrott, N.H. Fletcher. J. Chem. Phys., 50, 2344 (1969).

[11] W.T. Thompson, S.N. Flengas. Can. J. Chem., 49, 1550 (1971).

[12] F. Grønvold, E.F. Westrum. J. Chem. Therm., 18, 381 (1986).

[13] С.И. Садовников, А.В. Чукин, А.А. Ремпель, А.И. Гусев. ФTT, 58, 32 (2016).

[14] А.И. Гусев, С.И. Садовников, А.В. Чукин, А.А. Ремпель. ФTТ, 58, 246 (2016).

[15] X'Pert HighScore Plus. Version 2.2e (2.2.5). (C) 2009 PANalytical B.V. Almedo, the Netherlands.

[16] Ю.Ю. Лурье. Справочник по аналитической химии (М., Химия, 1989).

[17] C.H. Liang, K. Terabe, T. Hasegawa, M. Aono. Nanotechnology, 18, 485202 (2007).

[18] D. Wang, L. Liu, Y. Kim, Z. Huang, D. Pantel, D. Hesse, M. Alexe. Appl. Phys. Lett., 98, 243109 (2011).

[19] A.N. Belov, O.V. Pyatilova, M.I. Vorobiev. Adv. Nanoparticles, 3, 1 (2014).

Редактор Г.А. Оганесян

\section{Orientation relationships at structural transformation of monoclinic and cubic phases in silver sulfide}

\section{S.I. Sadovnikov, A.A. Rempel}

Institute of Solid State Chemistry, Ural Branch of the Russian Academy of Sciences, 620990 Ekaterinburg, Russia

Abstract Abstract Based on the experimental data on hightemperature $X$-ray diffraction and high resolution transmission electron microscopy of silver sulfide, the orientation relationships between the low-temperature monoclinic semiconductor acantite $\alpha-\mathrm{Ag}_{2} \mathrm{~S}$ and the high-temperature body-centered argentite $\beta-\mathrm{Ag}_{2} \mathrm{~S}$ are determined. It is found that, in contrast to acanthite, the possible distances between silver atoms in a cubic argentite are too small for the positions of the metal sublattice to be occupied by $\mathrm{Ag}$ atoms with a probability of 1 . It is shown that the acanthite $(010)$ and (001) atomic planes are parallel to the planes (11 0$)$ and (221) of argentite, respectively. The orientational relationships found between acanthite and argentite are important for understanding the physical action of the $\mathrm{Ag}_{2} \mathrm{~S} / \mathrm{Ag}$ heteronanostructure, considered as a potential basis for creating resistive switches and nonvolatile memory devices. 